\title{
Núcleos familiares concomitantes: (im) possibilidade de proteção jurídica
}

\section{Concomitant families: (in) ability of legal protection}

\author{
Luciana Poli ${ }^{*}$ \\ César Fiuza**
}

\section{Resumo}

O estudo analisa algumas decisões do Superior Tribunal de Justiça que, sob o fundamento da ausência da fidelidade - considerada requisito para configuração da união estável -, afastam a proteção jurídica a núcleos familiares paralelos. Apresenta o trabalho a noção de pânico moral, fenômeno que possivelmente explicaria a postura conservadora de algumas instituições jurídicas. Discutese a concepção da monogamia como princípio estruturante do Direito de Família, sugerindo que a família, como núcleo de peculiaridade dinâmica, pode assumir múltiplos contornos. Como agrupamento de pessoas comprometido em uma união estável, voluntária e cooperativa, que cumpre a função de promover e proteger seus integrantes, a família não há de ser tida apenas como elemento dado pelo legislador, resultando, também, de escolhas nas relações intersubjetivas que podem transcender ao modelo formulado pelo legislador.

Palavras-chave: Família. União estável. Monogamia. Pânico moral. Direitos humanos.

\section{Abstract}

The study examines some decisions of the Superior Court of Justice, which on the grounds of lack of fidelity - considered requisite for a civil union - remove

Professora da PUC-MINAS. Pós-Doutora pela UNESP (Bolsista da CAPES/PNPD). Doutora em Direito Privado pela Pontifícia Universidade Católica de Minas Gerais. Mestra em Direito e Instituições Políticas pela Universidade FUMEC/MG. Belo Horizonte - Minas Gerais - Brasil. E-mail: lucostapoli@yahoo.com.br

* Doutor em Direito pela UFMG. Professor titular de Direito Civil na Universidade FUMEC, associado na UFMG e adjunto na PUCMG. Professor colaborador na UNIPAC. Parecerista e consultor jurídico. Belo Horizonte - Minas Gerais - Brasil. E-mail: lucostapoli@yahoo.com.br 
from legal protection parallel households. The work presents the notion of moral panic, a phenomenon that possibly explains the conservative stance of certain legal institutions. It discusses the concept of monogamy as a structuring principle of family law, suggesting that family, as a core of dynamic peculiarity, may take multiple contours. As a group of people committed to a stable, voluntary and cooperative union, whose function is to promote and protect its members, family is not to be taken only as an element given by the legislature, also resulting from choices in interpersonal relations that can transcend the legal model.

Keywords: Family. Civil Union. Monogamy. Moral Panic. Human Rigths.

\section{Introdução}

A compreensão e aceitação das múltiplas dimensões que pode assumir a família se perfilham como uma das muitas inquietações que assombram as ciências sociais contemporâneas. Pretende-se nesse trabalho investigar a possibilidade de reconhecimento de direitos a núcleos familiares concomitantes, considerando os novos contornos principiológicos do Direito de Família. Entende-se a família, qualquer que seja sua forma, como a mais importante forma de agregação humana, por ser o núcleo primevo de promoção dos direitos fundamentais.

A partir de algumas decisões do Superior Tribunal de Justiça, evolvendo famílias paralelas, analisa-se a fidelidade como elemento caracterizador ou não da união estável, a impedir o reconhecimento de núcleos familiares concomitantes. Discute-se, assim, a concepção da monogamia como princípio estruturante do Direito de Família, sugerindo que a família, como núcleo de peculiaridade dinâmica, pode assumir múltiplos contornos.

Apresenta-se a noção de pânico moral, fenômeno que possivelmente explicaria a postura conservadora de algumas instituições jurídicas. Analisa-se, também, a noção de autonomia privada como elemento de um processo progressivo de efetivação das garantias constitucionais, a permitir ao indivíduo seu desenvolvimento segundo seu próprio projeto de vida, de acordo com sua situação e possibilidade, 
independente de qualquer modelo vinculado a uma visão particular de mundo.

Procurar-se-á demonstrar que a família, como espaço primevo de efetivação dos direitos fundamentais, além de propiciar afeto, amor e cooperação entre seus membros, assume seu papel promocional ao possibilitar o livre desenvolvimento da personalidade de seus membros, merecendo, assim, o respaldo do Direito e do Poder Judiciário independentemente da forma que possa assumir.

\section{Direito fundamental à família: faceta dos direitos humanos}

Considerando a importância conferida à família, como núcleo e origem da sociedade e peça fundamental para a formação e desenvolvimento da personalidade, diversos documentos internacionais reconhecem sua proteção no âmbito dos direitos humanos.

A Declaração Universal dos Direitos Humanos (2015, on-line) proclama que homens e mulheres têm o direito a contrair matrimônio e fundar uma família, sem quaisquer restrições. Considera também a família como núcleo natural e fundamental da sociedade, com a merecida proteção, tanto da própria sociedade como do Estado.

Na mesma esteira, no art. 23, o Pacto Internacional dos Direitos Civis e Políticos (2015, on-line) reconhece a família como elemento natural e fundamental da sociedade, assegurando, a todos, o direito à constituição de família. Proclama também o artigo 8 da Convenção Europeia dos Direitos Humanos o direito ao respeito à privacidade e à vida familiar como consectários à sociedade democrática.

Dada à relevância da proteção da família, a Convenção Americana de Direitos Humanos (Pacto de San José da Costa Rica) o assegura que este direito jamais será suspenso, nem mesmo em caso de guerra, de perigo público, ou de outra emergência.

Para Barros (2003, p. 45), o direito à constituição de família é, indubitavelmente, um direito humano fundamental e o direito de família, 
pode ser considerado como o mais humano dos direitos e acrescenta: "os direitos humanos repelem a exclusão de quaisquer entidades familiares verificáveis na evolução da família humana".

A constitucionalização dos direitos humanos que gozam de alto grau de justificação ao longo da história e que são reconhecidos como condição para o exercício dos demais direitos representam os direitos fundamentais de uma nação. Haveria, dessa forma, "um conteúdo mínimo de direitos fundamentais que caracterizam o direito de um Estado Democrático" (SAMPAIO, 2005, p. 17).

Nesse sentido, clara a proteção conferida à família no ordenamento jurídico brasileiro pela Constituição da República/88 (art. 226) como direito fundamental. A efetividade dos Direitos Humanos não pode ser isolada dos grandes problemas da atualidade, dentre os quais se destaca a multiplicidade das formas de família e a necessidade e seu reconhecimento e proteção. Como adverte Bobbio (2004, p. 68), "o problema fundamental em relação aos direitos do homem, hoje, não é tanto o de justificá-los, mas o de protegê-los".

Neste sentido, há que se reconhecer o direito de toda pessoa de viver e desenvolver-se no seio de uma estrutura familiar. 0 desenvolvimento pleno da personalidade e a formação da subjetividade dependem em grande medida da inserção familiar. Portanto, a família, quaisquer que sejam as feições que assume, merece ampla proteção de forma efetiva e concreta. Dessa maneira, qualquer Estado que considere os direitos humanos em sua configuração não pode subtrair a proteção às diversas concepções de família que se apresentam, sob pena de violar diretamente o ser humano.

\section{Breve perfil da família contemporânea}

A conformação da família contemporânea em muito difere do modelo oitocentista: patrimonial, hierarquizada, patriarcal. O conceito atual de família perpassa pela convivência pautada na solidariedade em função da afetividade representada por laços emocionais conjuntos. A 
família deve ser encarada como a comunidade de vida material e afetiva entre seus integrantes, união de esforços para o desenvolvimento de atividades materiais e sociais, convivência que promove mútua companhia, apoio moral e psicológico, na busca do melhor desenvolvimento da personalidade dos indivíduos que a compõem.

A ideia de família baseada na procriação e assistência à prole é ultrapassada. A família que se busca fomentar é aquela comprometida em uma união estável, voluntária e cooperativa que cumpre a função de promover e proteger seus integrantes, um organismo solidário.

A existência da família é essencial ao processo de desenvolvimento psíquico do indivíduo (LACAN, 2002); é um complexo espaço relacional e afetivo; o lócus primeiro de transmissão da cultura, no entanto, a própria evolução da cultura, de geração a geração, transforma e reconstrói a família. Na constituição de família está implícito o desejo dos indivíduos de compartilharem a mesma vida - dividindo tristezas, alegrias, fracassos, sucessos, pobreza e riqueza - e, enfim, de formarem um novo organismo distinto de suas individualidades (GAMA, 2001, p. 158).

Segundo Tepedino (1999, p. 341), para que se possa denominar um grupo de pessoas de família, faz-se necessária a presença de, ao menos, dois requisitos: (i) afetividade e (ii) estabilidade. No mesmo sentido, Lobo (2004, p. 505), para o qual qualquer entidade que preencha os requisitos da afetividade, estabilidade e ostensividade, é uma entidade familiar merecedora da proteção conferida pelo art. 226 da Constituição da República de 1988.

A família, em tese, oferece ao indivíduo um bem estar que noutra parte ele dificilmente encontra; é um asilo de paz e de conforto que o alenta nos conflitos sociais, intelectuais e psicológicos da vida. Ainda que, em alguns períodos da história, sob a forte influência de fenômenos sociais, a família tenha sido seriamente ameaçada, por gerar absurdas obrigações morais e econômicas, ela triunfou (COGLIOLO, 2004, p. 213).

Apesar da suposta desordem que hoje se atribui à família, pesquisas sociológicas demonstram que é "amada, sonhada e deseja por homens, mulheres e crianças de todas as idades, de todas as 
orientações sexuais e de todas as condições" (ROUDINESCO, 2003, p. 198).

O conceito de família hoje decorre do seguinte: família para a promoção do indivíduo, sua autonomia e pleno desenvolvimento da personalidade; família sem necessário casamento, pautada na igualdade entre os filhos e entre os genitores. Em todos os lares onde houver pessoas ligadas, seja por laços de sangue ou não, unidas pelo afeto, pelo plano de concretização das aspirações de cada uma delas e daquele núcleo como um todo, concatenadas e organizadas econômico e psicologicamente, haverá uma família.

Nessa perspectiva, família é todo agrupamento de pessoas comprometido em uma união estável, voluntária e cooperativa, que cumpre a função de promover e proteger seus integrantes, um organismo solidário. A família não pode ser tida apenas como elemento dado pelo legislador, mas deve ser revelada, também, pela observação social dos fatos nas relações intersubjetivas.

Há, assim, que privilegiar a expressão da liberdade no seio da família, reconhecendo aos seus integrantes a possibilidade de determinar a forma de constituição e direção da vida familiar, possibilitando-Ihes a interpretação das exigências de cada qual na busca do objetivo comum deste núcleo solidário e cooperativo, bem como da busca das aspirações individuais. O caráter da família mostra-se dinâmico, a possibilitar-lhe inúmeras e inusitadas feições. Por consequência, não se pode negar que a norma jurídica familiar deverá assumir também contornos dinâmicos, sob pena de regrar o vazio, afinal, a família se submete a constantes movimentos sociais, históricos e valorativos que importam diuturnas mutações.

A família, segundo a concepção ora tratada, há de ser espaço de fomento da dignidade da pessoa humana, de realização e construção da personalidade, da busca da satisfação pessoal e social. Uma das facetas da nova família que se desenha é justamente a mudança de pressupostos. Não se trata mais de uma instituição nascida do casamento 
legal heterossexual e, sim, da disposição em partilhar sentimentos, momentos, cuidados.

Qualquer que seja sua configuração é a família a mais importante forma de agregação humana, o núcleo primeiro de promoção dos direitos fundamentais. Independentemente do arranjo que possa assumir, é o espaço indispensável para a garantia do desenvolvimento digno da pessoa humana. A proteção de seus membros dar-se-á, em primeira instância, pelo respeito à autonomia de cada um. O comprometimento com os princípios constitucionais, em especial a dignidade da pessoa humana e o livre desenvolvimento da personalidade, tem como escopo compreender a família funcionalizada como instrumento de concretização da liberdade (VILLELA, 1980, p. 11). Como ressalta Perlingieri (2002, p. 125): "A liberdade na família encontra na unidade e nos relativos deveres não apenas o limite, mas a função, o fundamento para a própria titularidade".

\section{União estável no Brasil: requisitos legais}

O art. 1.723 do Código Civil reproduz o conceito já consolidado pela Lei $n^{\circ}$ 9.278, de 1996, e elenca como elementos essenciais para a configuração de união estável a convivência pública, contínua e duradoura estabelecida com o objetivo de constituição de família.

A união estável corresponde de certa maneira a um casamento de fato, isto é, configura-se como um vínculo social sólido capaz de revelar a inequívoca vontade do par de estabelecer um núcleo familiar. A presença dos requisitos legais revela a exigência de se estabelecer prova segura para o reconhecimento de sua existência e, consequentemente, para a concessão dos direitos assegurados aos companheiros. Não constitui união estável o relacionamento entretido sem a intenção clara de constituir um núcleo familiar. A união estável indica uma comunhão de vida e de interesses, reclamando não apenas publicidade e estabilidade, mas, sobretudo, um nítido caráter familiar, evidenciado pela affectio maritalis. 
A publicidade desponta pela notoriedade da relação no meio social no qual se insiram os companheiros, a unidade do relacionamento, denotando a ideia da posse do estado de casados. Apesar de a lei não exigir decurso de lapso temporal mínimo para a caracterização da união estável, a relação não deve ser efêmera, circunstancial, eventual, mas habitual, contínua, duradoura, prolongada no tempo.

Alinhadas a esses aspectos, há de ser caracterizada a vida em comum, a mútua assistência, a presença do enlaçamento de vida, do comprometimento recíproco, a divisão de responsabilidades, enfim, um convívio consolidado e norteado a metas comuns de cooperação e solidariedade.

O juiz, para o reconhecimento da união estável, deverá analisar as circunstâncias fáticas de cada caso concreto, levando em consideração, por exemplo, a vida em comum; a existência de filhos; a notoriedade da convivência; o contrato escrito reconhecendo a união; os atos e os negócios jurídicos que se referem à união, além do elemento subjetivo já assinalado, qual seja, o animus de constituir família, assumido perante a sociedade, com a concessão mútua do tratamento, da consideração, do respeito que se dispensam, reciprocamente, os esposos (VELOSO, 2003).

É preciso considerar, entretanto, que o conceito de comunidade ou comunhão de vida tem sofrido profundas mudanças na contemporaneidade. Atenta a essa tendência, já se dispensa a convivência sob o mesmo teto para a caracterização da união estável, exigindo-se que as relações se pautem pela regularidade, habitualidade e que sejam conhecidas ao menos por um pequeno círculo social.

Desse modo, tem-se que, se configurada a relação como contínua, notória, pautada na existência de uma cooperação econômica, por meio do auxílio mútuo, inferindo-se o ânimo das partes em manter a estabilidade do convívio, possível o seu reconhecimento como união estável, ainda que os conviventes residam em locais distintos. 


\section{Infidelidade: elemento descaracterizador do núcleo familiar - a posição do superior tribunal de justiça}

Apesar da enumeração legal dos requisitos para a configuração da união estável, algumas decisões do Superior Tribunal de Justiça apontam a fidelidade também como um dos requisitos para seu reconhecimento. Da análise dos acórdãos estudados ${ }^{1}$, de lavra da Terceira Turma do Superior Tribunal de Justiça, infere-se a posição da ministra Nancy Andrighi:

A análise dos requisitos ínsitos à união estável deve centrar-se na conjunção de fatores presentes em cada hipótese, como a affectio societatis familiar, a participação de esforços, a posse do estado de casado, a continuidade da união, a fidelidade, entre outros, sendo dispensável a formação de patrimônio comum (grifo nosso).

Recentemente, a mesma Turma desta Corte $^{2}$ rejeitou um pedido de reconhecimento de união estável por falta de fidelidade. O Tribunal negou o reconhecimento de união estável porque o falecido mantinha outro relacionamento estável com terceira.

No caso em análise, uma mulher interpôs recurso especial contra acórdão do Tribunal de Justiça de Minas Gerais, que já havia negado o pedido de reconhecimento por entender que seu relacionamento com o finado teria sido apenas um namoro, sem objetivo de constituição de família.

No recurso, a autora-recorrente sustentou que manteve convivência pública, duradoura e contínua com o finado de julho de 2007 até o seu falecimento, em 30 de novembro de 2008, e que o dever

Recurso Especial n. 1.353.039/MS (2011/0221568-0); Recurso Especial n. 1157273/RN (2009/0189223-0); Recurso Especial n. 1107192/PR (2008/0283243-0).

2 Acordão não divulgado. Notícia veiculada no site do STJ no dia 20 de maio de 2014, às 15h58min. Disponível em: <https://www.facebook.com/notes/superiortribunal-de-justiça-stj/terceira-turmanega-reconhecimento-de união-estável-por-falta-de-fidelidade/10154207197210397>. Acesso em: 2 jun. 2014. 
de fidelidade não estaria incluído entre os requisitos necessários à configuração da união estável.

A outra companheira contestou a ação, alegando ilegitimidade ativa da autora, que seria apenas uma possível amante do finado, com quem ele viveu em união estável desde o ano 2000 até o seu falecimento.

Segundo a ministra Nancy Andrighi, relatora do caso, a controvérsia do recurso consistia em definir se a união estável pode ser reconhecida entre as partes, mesmo diante da inobservância do dever de fidelidade pelo falecido, que mantinha outro relacionamento estável com terceira, sendo que os dois relacionamentos simultâneos foram efetivamente demonstrados nos autos. A ministra assim argumentou:

Conforme destaquei no voto proferido no REsp 1.157.273, a análise dos requisitos para configuração da união estável deve centrar-se na conjunção de fatores presentes em cada hipótese, como a affectio societatis familiar, a participação de esforços, a posse do estado de casado, a continuidade da união, e também a fidelidade.

Para a ministra, uma sociedade que apresente como elemento estrutural a monogamia não pode atenuar o dever de fidelidade - que integra o conceito de lealdade e respeito mútuo - para inserir no âmbito do Direito de Família relações afetivas paralelas.

Citando precedentes, Nancy Andrighi alertou que, ao analisar as lides que apresentam paralelismo afetivo, deve o juiz, atento às peculiaridades de cada caso, "decidir com base na dignidade da pessoa humana, na solidariedade, na afetividade, na busca da felicidade, na liberdade, na igualdade, bem assim, com redobrada atenção ao primado da monogamia, com os pés fincados no princípio da eticidade".

A ministra concluiu o voto ressaltando que seu entendimento não significa dizer que a relação mantida entre a recorrente e o falecido mereça ficar sem qualquer amparo jurídico, pois "ainda que ela não tenha logrado êxito em demonstrar, nos termos da legislação vigente, a existência da união estável, poderá pleitear em processo próprio o reconhecimento de uma eventual sociedade de fato". 
O voto da relatora foi acompanhado de forma unânime na Turma e reforçado por um comentário do ministro Sidnei Beneti. Para ele, divergir da relatora neste caso seria legalizar a "poligamia estável". O posicionamento da ministra suscita algumas considerações críticas:

$1^{\text {a }}$. tanto a Lei ${ }^{\circ}$ 9.278 de 1996, como o Código Civil não mencionam expressamente a observância do dever de fidelidade recíproca para que possa ser caracterizada a união estável;

$2^{a}$. ainda que se entenda que a fidelidade seja inerente ao dever de respeito e lealdade entre os companheiros, sua inobservância não é suficiente para descaracterizar a união estável;

$3^{a}$. no caso dos autos, a própria ministra admite que a relação não deve permanecer à margem de amparo jurídico, mas, de forma teratológica, recomenda o reconhecimento como sociedade de fato, o que implica retrocesso histórico em prejuízo da prestação jurisdicional;

$4^{\text {a }}$. a dignidade humana, a solidariedade, a afetividade e a busca da felicidade orientam a decisão em sentido contrário;

$5^{a}$. a monogamia não pode ser considerada um princípio;

$6^{a}$. trata-se não de descaracterizar união estável por falta de requisitos, mas de não se admitir uniões paralelas.

A infidelidade de um dos companheiros, quando ignorada pelo outro, não é elemento suficientemente robusto para afastar o caráter sólido de qualquer relacionamento. A fidelidade, tanto na união estável como no próprio casamento, é presumida, ou seja, o descumprimento unilateral desse dever não implica, por si só, a ruptura do caráter conjugal estável.

A fidelidade ou a infidelidade é uma escolha pessoal, insuscetível do controle do Estado e do Direito, e negar direitos, considerando-se o comportamento fiel ou infiel na família, é retroceder e ignorar conquistas históricas, como o abandono da discussão da culpa na separação.

Desde a edição da Lei do Divórcio, em 1977, teme-se que a família brasileira desmorone. Agora parece haver o temor de que, admitir 
uniões paralelas, seria incentivar o abandono do modelo idealizado de família. De fato, aí reside a questão: a família não se submete a modelos estanques e herméticos; ao contrário, a diversidade das estruturas e configurações familiares demonstra a imensa plasticidade dos grupos domésticos e das múltiplas possibilidades de organização da reprodução biológica e social em uma mesma sociedade (SCOTT, 2012).

Ainda que tenham ocorrido avanços na percepção social sobre as múltiplas formas de família, não há dúvida de que as vidas amorosas ainda são vistas como reduzidas à sexualidade, sob a necessidade de controle. Há que recusar padrões hegemônicos de definição das relações legítimas, pautadas ainda por ditames de raízes religiosas.

Contrariando as previsões de Bordieu (1993, p. 32-36), a família não tende a desaparecer, mas incorpora novas possibilidades de grupos familiares que devem ser enaltecidos, protegidos e incentivados. Mesmo que na sociedade ocidental a figura do pai, da mãe e dos filhos ainda possa constituir um modelo idealizado de família, esta conformação na prática não faz parte da experiência de um grupo já considerável de indivíduos (UZIEL; MELLO; GROSSI, 2006). A família há muito se transformou de unidade natural, arraigada em processos biológicos, em unidade histórica e socialmente construída. Hoje já se encontra consolidada em múltiplas feições a merecer o amparo do ordenamento jurídico, conforme preceitua a Constituição da República de 1988.

\section{6 resguardo da fidelidade: pânico moral?}

Refletindo sobre como a sociedade reage a determinadas situações e identidades sociais que presume representarem alguma forma de perigo à ordem tradicionalmente aceita como standart tolerável e desejável, Cohen (1972, p. 14) utilizou o termo pânico moral para caracterizar a maneira pela qual a mídia, a opinião pública e os agentes estatais de controle social e judicial reagem a determinados rompimentos de padrões morais ou normativos. 
O pânico moral pode ser compreendido, numa acepção mais abrangente, como o consenso, partilhado por um número substancial de membros de uma sociedade, de que determinada categoria de indivíduos estaria ameaçando a estrutura social e a ordem moral. A partir dessa suposta ameaça, confabulam que seria necessário o fortalecimento do aparato de controle social, provocando a promulgação de novas leis, orientando a atuação estatal por políticas públicas capazes de imprimir hostilidade e condenação pública a determinado estilo de vida (GOODE; BEM-YEHUDA, 2003, p. 29-30).

Esse estado de pânico pode ser desencadeado por uma determinada condição, um episódio, uma pessoa, um agrupamento ou uma formação social que passam a ser concebidos como uma ameaça aos valores já consagrados e à ordem social hegemônica, ordem apresentada de forma estilizada e estereotipada pela mídia de massa, apoiada pelo Estado e, consequentemente, por seu aparato judicial.

O objeto do pânico pode ser um fenômeno absolutamente novo ou algo que já existia na sociedade há muito tempo, ofuscado e reprimido, mas que, desencadeado por algum movimento ou fato, ganhou notoriedade. As repercussões geradas são diversas; por vezes o pânico desaparece e é esquecido, permanecendo apenas no imaginário cultural como no folclore e na memória coletiva. Outras vezes, gera efeitos mais duradouros, capazes de produzir mudanças nas políticas públicas, na política legal e social ou, até mesmo, na forma como a sociedade se compreende (COHEN, 1972, p. 9).

Os estudos de Cohen (1972) mostram que as reações a comportamentos não convencionais quase sempre são marcados por julgamentos não realistas e imponderados a respeito das consequências coletivas de estilos de vida particulares. A reação social a um fenômeno aparentemente perigoso surge não tanto do perigo real, mas do temor de que ameace posições, interesses, ideologias e valores (GOODE; BEM-YEHUDA, 2003, p. 29-30). A propagação do sentimento de pânico suscita a necessidade de afirmação dos valores tradicionais, da ordem social idealizada e supostamente desejável (THOMPSON, 1998, p. 4). 
A insistente posição do Superior Tribunal de Justiça, em evocar a fidelidade como requisito à configuração ou caracterização da união estável e repudiar o reconhecimento de eventuais relações estáveis paralelas, fundamentando seus julgados em valores morais que não correspondem ao pulsar dos anseios do homem contemporâneo, parece revelar sua crença de que a família e, consequentemente, toda a sociedade, estaria sob premente ameaça.

A própria união estável, por seu caráter libertário, seja hétero ou homossexual, suscita temores com relação à sobrevivência da instituição familiar em seu papel de mantenedora de toda uma ordem social, imantada de valores tradicionais. Revela-se, assim, uma tendência em prestar, à união estável, um papel conformador de alinhamento comportamental, contrariando sua natureza de união livre, voltada a privilegiar a reunião afetiva, a ajuda mútua, a solidariedade, o companheirismo.

O conhecimento sobre a noção de pânico moral, e sua provável disseminação ou reflexos em segmentos do próprio Poder Judiciário, pode colaborar para a compreensão do comportamento de parte da coletividade diante das pressões sofridas por mudanças na estrutura social e na construção das individualidades, de projetos de vida, que escapem ao standard, ao modelo que se acostumou a sublinhar.

Revela ainda o incessante movimento de controle social e intervenção da vida privada perpetuado pelo Estado pelas mãos de julgadores, presumivelmente instituídos do poder de construir fronteiras a delimitar a zona possível de formação da vida familiar, contrariando o comando constitucional de não interferência na comunhão de vida instituída pela família.

O pânico desencadeia um processo de busca de permanência num horizonte relacional convencional, considerando que, na sociedade contemporânea visivelmente caótica, a família passa a ser reivindicada como o único valor seguro ao qual ninguém quer renunciar.

A família parece ser uma instituição perene, mas é mutável, maleável e dinâmica, modificando-se constantemente. Contrariamente 
ao que se supõe, é a instabilidade da compreensão social do que constitui uma família adequada e quais seriam as relações familiares convenientes, que permitiu sua sobrevivência ao longo do tempo como instituição forte e simbolicamente rica (MUNOZ-DARDÉ, 2001, p. 322).

Os caminhos na configuração de um projeto pessoal ou familiar não são estanques, podem corresponder a padrões já estabelecidos e amplamente disseminados ou podem se configurar, à primeira vista, dentre uma ampla pauta de possibilidades complexas, mas não por isso podem ser desvalorizados ou renegados.

O Direito não pode enrijecer-se, furtando-se ao compromisso de perceber a realidade. Há de ser inquieto, curioso, atento, permeável, sob pena de tornar-se inútil. A família contemporânea apresenta um grande desafio: por um lado uma combinação explosiva de crescimento das possibilidades de arranjos, e, por outro, o acirramento das posições conservadoras entrincheiradas na manutenção de um modelo supostamente seguro. Esse efeito de escalada contrastiva reflete-se, do mesmo modo, no crescimento da violência familiar e homofóbica (DUARTE, 2009).

A margem de ação pessoal na configuração familiar, balizada por ditames morais e regras relacionais, quase sempre associada a configurações de valores religiosos de caráter apriorístico, coletivo e imperativo, precisa ser rompida. Afeto, amor, paixão, desejo, compromisso, carinho, lealdade, tantos valores considerados essenciais são redesenhados e atualizados no pulsar de uma sociedade cada vez mais energizante e, por vezes, caótica, produzindo roteiros dramáticos e soluções vivenciais bem diversas, que reclamam resposta e amparo do Direito.

O parentesco, por exemplo, pode não ser mais a junção de laços de sangue com laços de afinidade e, em definitivo, torna-se apenas um laço de afinidade, uma escolha pessoal. A humanidade não se desenvolve sob o regime de uma uniforme monotonia, mas por meio de modos extraordinariamente diversificados de sociedades e de 
civilizações. Por sua vez, as escolhas da sociedade não pertencem aos sábios, mas aos cidadãos (LÉVI-STRAUSS, 1978, p. 57).

De toda sorte, a família, qualquer que seja sua formatação, ainda é a melhor contrapartida à tendência de autonomização crescente da contemporaneidade. O amor constitui "a melhor ideologia contra os perigos da individualização" (BECK, 2011, p. 44) porque promete aos "indivíduos singulares reencontrar uma dimensão de comunidade" (BECK, 2011, p. 44), por isso há de ser sempre promovida, aplaudida, não repudiada.

\section{Monogamia no ordenamento jurídico brasileiro: princípio?}

O enfrentamento do tema proposto acaba por conduzir o trabalho a um dos assuntos mais tormentosos no Direito de Família: a compreensão da importância e do alcance da monogamia no sistema jurídico brasileiro, que tem sido elevada à categoria de princípio estruturante do próprio ramo.

A monogamia deve continuar sendo utilizada como critério de exclusão da tutela jurídica de entidades familiares que se formem simultaneamente, considerando o caráter promocional da família e do indivíduo conferido pela Constituição da República de 1988 ? O eixo estrutural da organização jurídica da família deve centrar-se na monogamia ou na promoção de seus membros?

Elevar a monogamia à categoria de princípio é perpetuar o que o texto constitucional não disse; é vendar os olhos para inúmeras realidades familiares; é perseguir resultados desastrosos; é negar o reconhecimento e proteção a diversos núcleos familiares. Em sentido oposto, Pereira (2006, p. 848-849) afirma que a monogamia funciona como um interdito proibitório a impedir o estabelecimento de relações paralelas, e sua natureza de princípio evidencia a não recepção pelo Estado da possibilidade de laços afetivos simultâneos. 
Princípios têm conteúdo normativo; pertencem ao plano deôntico e possuem tônus de coercibilidade; importam um dever-ser, que propõe uma avaliação de lícito ou ilícito. Pode-se impor a alguém a constituição de laços únicos de afeto? Deve-se abandonar conquistas históricas, como a atribuição de culpa na separação e seus nefastos efeitos? Seria matéria de Direito preconizar a imposição de um determinado estilo de vida ou limitar os elos afetivos?

A monogamia apresenta-se como um valor, resquício da influência religiosa no ordenamento jurídico. Não parece que tenha natureza normativa, apresentando-se como um valor a ser considerado e desejado. Valores pertencem ao âmbito da axiologia, a refletir o conceito de bom; suas avaliações serão consideradas a partir do melhor ou pior (LANA; RODRIGUES JÚNIOR, 2010, p. 267).

Princípio, como dever-ser, é para todos, é vinculativo e não admite juízo acerca da sua qualidade. Já o valor exprime uma avaliação que não permite aplicá-lo cogentemente a todos indistintamente. Aquilo que é bom para uns, não o será para outros, embora possa indicar relações de preferência. Os valores não indicam consequências jurídicas pelo seu não cumprimento, porque o comportamento que revela é desejado, mas não tem caráter normativo.

A monogamia é um sentimento de disposição e entrega emocional, cuja regulamentação escapa ao objetivo do Direito. É desejada na família, mas pertence, como assinalado, ao plano da axiologia, daquilo que é bom, não podendo ser considerada um princípio, uma norma passível de coerção. Ainda que a inobservância da fidelidade cause dor, frustração ou sofrimento a alguém, não é ato ilícito, se for opção do casal. O amor existe enquanto fruto da espontaneidade. As decepções, desilusões, frustrações, ausências são fatos da vida.

Os direitos à vida íntima e de viver na sombra e na penumbra consistem em direitos da personalidade. É válido, portanto, manter fora do alcance público aquilo que diz respeito à intimidade das pessoas, ao seu modo de ser na vida particular (ARENDT, 2000, p. 68). 
A monogamia somente é relevante para o Direito de Família quando seu avesso violar a dignidade da pessoa humana. Não cabe ao Estado exercer o papel de tutor na construção afetiva coexistencial. A negação ao desejo mútuo, correspectivo, neste caso, já se apresenta por meio do juízo de reprovação social movido por uma moral ética (PIANOVSKI, 2006, p. 198-199). Não é afeto ao Direito sentir ciúmes pela parte supostamente traída e sim dar azo à nova quadra histórica da liberdade amorosa e da proteção à dignidade da pessoa humana:

Mais do que fazer com que os indivíduos tenham direitos fundamentais e naturais, nós deveríamos tentar imaginar e criar um novo direito relacional que permitiria que todos os tipos possíveis de relações pudessem existir e não fossem impedidos, bloqueados ou anulados pelas instituições relacionais empobrecedoras (FOUCAULT, 1994, p. 1.129).

A monogamia institucionalizou-se capturada como estratégia de controle moral, de modo a promover a cristalização de territórios existenciais, espécie de coágulo do tecido social, que, pelo uso repetido, passou a referendar determinado modo de vida; formas de relação, laços de conjugalidade, que, em algum momento, mostraram-se satisfatórios.

Hoje, é inegável a fissura no discurso jurídico que a sustenta, antes apresentado como monolítico e inquebrantável. A invisibilidade de realidades familiares antes ofuscadas, escondidas, marginalizadas, veio à tona. É hora de o Direito se verter mais uma vez à força social. Há que desconstruir os lugares de não Direito, refutar a externalidade da situação de sujeito de direito dos indivíduos nas salientes demarcações e contornos atuais da conjugalidade:

Nos esquecemos rapidamente os velhos poderes que não se exercem mais, os velhos saberes que não são mais úteis, mas em matéria moral, não deixamos de depender de velhas crenças, nas quais nem mesmo cremos mais, e de nos produzirmos como sujeitos em velhos modos que não correspondem aos nossos problemas (DELEUZE, 1988, p. 114). 
O projeto democrático emancipatório deve-se expandir para além da praça e alcançar as casas e as relações coexistenciais, a promover o exercício da plena cidadania. O Direito deve mergulhar em águas turbulentas, enveredar-se por caminhos não tão bem torneados, abandonar o flúmen tranquilo de cognições já consolidadas.

Surpreendentemente, a Terceira Turma do Superior Tribunal de Justiça considerou admissível que a impenhorabilidade do bem de família atinja simultaneamente dois imóveis do devedor - aquele em que ele mora com sua esposa e outro no qual vivem suas filhas nascidas de relação extraconjugal ${ }^{3}$.

Essa decisão não reflete a orientação majoritária do Tribunal, para o qual a capacidade de instituir novos valores, revolucionar costumes, revelar ideias e soluções originais soa como uma ameaça à ordem subjetiva conquistada. Revela-se, de forma geral, resistente e insensível a novas dobraduras, guardião de uma ordem moral monolítica.

É hora de abandonar o percurso conformista da humanidade, o desejo ao processo estratificante das instituições, a âncora invisível, o conforto arrimo do instituído, que reproduz sempre o mesmo, como se fosse único o modo de coexistência.

\footnotetext{
Notícia veiculada no site do STJ no dia 27 de maio de 2013: "STJ amplia o conceito de entidade familiar para proteção de bem de família". Disponível em: <https://pt-br.facebook.com/ notes/superior-tribunal-de-justi\%C3\%A7a-stj/stj-amplia-o-conceito-de-entidade-familiar-paraprote\%C3\%A7\%C3\%A3o-de-bem-de-fam\%C3\%ADlia/10152896540170397>. Acesso em: 2 jun. 2014. Em sentido oposto, Recurso Especial n. 912.926, Relator Ministro Luís Felipe Salomão, Quarta Turma, publicado em 07.06.2011, em cuja ementa se lê: "Direito de família. Reconhecimento de uniões estáveis simultâneas. Impossibilidade. Exclusividade de relacionamento sólido. Condição de existência jurídica da união estável. Exegese do $\S 1^{\circ}$ do art. 1.723 do Código Civil de 2002. 1. Para a existência jurídica da união estável, extrai-se, da exegese do $\S 1^{\circ}$ do art. 1.723 do Código Civil de 2002, fine, o requisito da exclusividade de relacionamento sólido. Isso porque, nem mesmo a existência de casamento válido se apresenta como impedimento suficiente ao reconhecimento da união estável, desde que haja separação de fato, circunstância que erige a existência de outra relação afetiva factual ao degrau de óbice proeminente à nova união estável. 2. Com efeito, a pedra de toque para o aperfeiçoamento da união estável não está na inexistência de vínculo matrimonial, mas, a toda evidência, na inexistência de relacionamento de fato duradouro, concorrentemente àquele que se pretende proteção jurídica, daí por que se mostra inviável o reconhecimento de uniões estáveis simultâneas."
} 
Mas em geral, o Poder Judiciário no Brasil mostra-se distante desse caminho. No Recurso Especial n. 1157273/RN, julgado pelo Superior Tribunal de Justiça, em maio de 2010, a relatora, ministra Nancy Andrighi, argumentou que, em razão do dever de lealdade e da adoção de um padrão familiar monogâmico, não se pode permitir o reconhecimento da existência de famílias simultâneas. A "segunda família" seria apenas uma sociedade de fato.

No caso, o falecido foi casado e, ao separar-se consensualmente da esposa, iniciou um relacionamento afetivo com outra mulher, que perdurou de 1994 até a data seu falecimento em 2003. Ocorre que, embora divorciados em 1999, a ex-esposa e o falecido voltaram a se relacionar, e esse novo relacionamento também durou até sua morte. Diante disso, as duas mulheres buscaram, mediante ação judicial, o reconhecimento de união estável e, consequentemente, o direito à pensão do falecido.

Ojuiz de primeiro grau, entendendo haver elementos inconfundíveis caracterizadores de união estável existente entre o de cujus e as demandantes, julgou ambos os pedidos procedentes, reconhecendo as uniões estáveis simultâneas e, por conseguinte, determinou o pagamento da pensão em favor de ambas, na proporção de cinquenta por cento para cada uma. Na segunda instância a sentença foi mantida.

No julgamento do caso, salientou a relatora que a análise dos requisitos ínsitos à união estável deve centrar-se na conjunção de fatores presentes em cada hipótese, como a affectio societatis familiar, a participação de esforços, a posse do estado de casado, a continuidade da união, a fidelidade, entre outros. Desse modo, entendeu que, no caso, a despeito do reconhecimento, na dicção do acórdão recorrido, da união estável entre o falecido e sua ex-mulher em concomitância com união estável preexistente por ele mantida com a recorrente, é certo que o casamento válido entre os ex-cônjuges já fora dissolvido pelo divórcio nos termos do art. $1.571, \S 1^{\circ}$, do Código Civil, rompendose, definitivamente, os laços matrimoniais outrora existentes. Destarte, a continuidade da relação sob a roupagem de união estável não se 
enquadra nos moldes da norma civil vigente (art. 1.724 do Código Civil), porquanto esse relacionamento encontra obstáculo intransponível no dever de lealdade a ser observado entre os companheiros. A decisão fundamentou-se, ainda, nos seguintes argumentos:

a) uma sociedade que apresenta como elemento estrutural a monogamia não pode atenuar o dever de fidelidade, que integra o conceito de lealdade, para o fim de inserir, no âmbito do Direito de Família, relações afetivas paralelas e, por consequência, desleais, sem descurar do fato de que o núcleo familiar contemporâneo tem como escopo a realização de seus integrantes, vale dizer, a busca da felicidade;

b) a relação mantida entre o falecido e a ex-esposa, despida dos requisitos caracterizadores da união estável, poderá ser reconhecida como sociedade de fato, caso deduzido pedido em processo diverso.

A solução sugerida pela ministra é teratológica: reconhece a existência de dois núcleos familiares, presentes os requisitos da estabilidade, ostensividade e affectio maritalis, mas retira de um dos elos afetivos a proteção jurídica conferida à família, em razão da ausência de fidelidade. Vale dizer, admite que, se houve amealhamento de patrimônio comum, a interessada deveria buscar as varas comuns, negando-lhe, assim, a proteção especial à família estabelecida constitucionalmente (art. 226, caput, da Constituição da República de 1988).

Essa decisão, na contramão do Direito de Família contemporâneo, privilegia os aspectos patrimoniais em detrimento da solidariedade e cooperação. O Direito de Família não deve permanecer no apego rígido à dogmática, o que tornaria o julgador cego à riqueza com que a vida real se apresenta. No caso, o falecido tinha a notável capacidade de conviver simultaneamente com duas mulheres, estabelecendo dois relacionamentos com todas as características de entidades familiares. Por que, cedendo à realidade, não se pode reconhecer como coexistentes duas entidades familiares simultâneas?

O fato é que essa realidade existe e deve-se pensar no caso concreto, nas peculiaridades de núcleo afetivo, analisando os diversos 
elementos de cada uma destas relações familiares simultâneas e considerando que, aos olhos da Constituição da República de 1988, o que importa é formação em si de um duradouro núcleo doméstico.

Nesse sentido, a liberdade na concepção, manutenção e atribuição de direitos às diversas formas de família deve ser vista como necessária para a promoção da dignidade, da autonomia privada, da solidariedade e do pleno desenvolvimento da personalidade dos seus membros. A construção da esfera existencial de cada um é processo complexo, permeado de situações jurídicas que eventualmente podem gerar conflitos. Não cabe ao Direito criar limites baseado em arquétipos de origem religiosa ou estritamente moral.

A Constituição da República de 1988 promove a proteção das pessoas, seres humanos, que formam núcleos domésticos concretos, singulares, imperfeitos. Do ponto de vista constitucional, o modo pelo qual se formam ou se mantêm esses núcleos é secundário.

\section{Conclusão}

O trabalho, partindo de uma leitura contemporânea da família, procurou retratar o papel funcional e promocional que desempenha, em busca, sobretudo, do fomento ao livre desenvolvimento de seus membros.

A função da família que se pretendeu desenhar é aquela que ultrapassa o âmbito das relações doméstico-patrimoniais hierarquizadas. Defendeu-se o núcleo familiar como espaço de cooperação mútua, na medida da capacidade de cada um de seus membros, de forma a propiciar, ainda, a realização da cidadania e da promoção da dignidade de cada um de seus componentes.

Nessa perspectiva, apresentou-se a família como agrupamento de pessoas comprometido em uma união estável, voluntário e cooperativo, que cumpre a função de promover e proteger seus integrantes, um organismo solidário. Buscou-se no estudo privilegiar um horizonte familiar 
que revalorize e veicule a solidariedade, a compreensão e, sobretudo, um espaço saudável para o livre desenvolvimento da personalidade e a construção plena da autonomia.

Se o conceito de família ultrapassou a formação constituída com o intuito procriativo e realização de interesses patrimoniais e religiosos para um refúgio eudemonista, as disposições normativas em Direito de Família devem ser lidas à luz de uma interpretação que considere o verdadeiro significado do conceito de família hoje, como instrumento devotado à tutela existencial das pessoas.

Neste contexto, a família contemporânea, fundada essencialmente na cooperação, ao assumir novos contornos, deve estar liberta das amarras impostas pela própria sociedade e pelo sistema jurídico encerrado. A promoção da dignidade humana se realizará, no seio da família, pelo reconhecimento pleno das opções individuais.

Não se defende um esvaziamento da participação do Estado na família, mas sim uma revisão de seus contornos, até mesmo porque a intervenção do Estado é necessária e, por vezes, essencial na proteção e promoção daqueles que se encontrem em situação de vulnerabilidade.

As transformações em curso nas relações sociais e nas instituições como a família geram pânicos morais, que acabam por culpabilizar determinados indivíduos por suas escolhas, controlar grupos estigmatizados e, mais grave ainda, negar direitos àqueles que os cercam.

A constituição do sujeito há de atravessar a moral estratificada de uma época e os procedimentos hegemônicos e moduladores que as instituições insistem em propalar.

A união estável como formação familiar vive um dilema: o flerte com a institucionalização confunde-se com a sedução da normalidade e seus supostos prazeres sem culpas, sem crises de consciência, com direitos previamente assegurados. Por outro lado, beneficia apenas os enquadrados em um esquema legal e convencional, deixando à margem aqueles que recusam o regramento e a suposta normalização 
de suas vidas amorosas, sob os quais, de certa forma, ainda restará o estigma da perversão sexual, por negarem a se submeter aos ditames da fidelidade.

Relembrando Milton (2002), aqueles que buscam resguardar a velha ordem social, recusando-se a assimilar a diversidade, deveriam reconhecer que o único paraíso que existe é o paraíso perdido.

O amor não aceita negociação, domínio e tirania mesmo pelo Direito. Ao contrário, invoca uma riqueza de possibilidades e remete à liberdade: de batalha, de esforço, de escolha e de produção de sentido para cada um de acordo com suas individualidades, suas opções, suas condições, suas possibilidades e interesses.

\section{Referências}

ALMEIDA, Renata Barbosa de; RODRIGUES JÚNIOR, Walsir Edson. Direito das famílias. Rio de Janeiro: Lúmen Júri, 2010.

ANDRADE, André Gustavo de. O princípio fundamental da dignidade humana e sua concretização judicial. Revista de Direito do Tribunal de Justiça, Rio de Janeiro, n. 58, p. 35-39, jan./mar. 2004.

ARENDT, Hannah. A condição humana. 10. ed. Tradução de Roberto Raposo. Rio de Janeiro: Forense Universitária, 2000.

BARROS, Sérgio Resende de. Direitos humanos: paradoxo da civilização. Belo Horizonte: Del Rey, 2003.

BARROS, Sérgio Resende de. Direitos humanos da família: dos fundamentais aos operacionais. In: GROENINGA, Giselle; PEREIRA, Rodrigo da Cunha (Org.). Direito da família e psicanálise: rumo uma nova epistemologia. Rio de Janeiro: Imago, 2003. p. 15.

BECK, Ulrich. A sociedade de risco: rumo a uma outra modernidade. Tradução de Sebastião Nascimento. 2. ed. São Paulo: Editora 34, 2011. 
BOBBIO, Norberto. Liberdade e igualdade. 2. ed. Rio de Janeiro: Ediouro, 1998.

BOBBIO, Norberto. A era dos direitos. Tradução: Carlos Nelson Coutinho. Rio de Janeiro: Campus, 2004.

BOURDIEU, Pierre. A propos de la famille comme catégorie réalisée. Persee Revues Scientifiques, Lyon, v. 100, p. 32-36, 1993.

CHEMAMA, Roland. Dicionário de psicanálise. Porto Alegre: Artes Médicas Sul, 1995.

COGLIOLO, Pietro. Lições de filosofia e de direito privado.

Tradução de Henrique de Carvalho. Belo Horizonte: Líder, 2004.

COHEN, Stanley. Folk devils and moral panics: the creation of mods and rockers. London: MacGibbon \& Kee, 1972.

CORDEIRO, Antonio Manuel da Rocha e Menezes. Da boa fé no direito civil. Lisboa: Almedina, 2007.

DELEUZE, Gilles. Foucault. São Paulo: Brasiliense, 1988.

DUARTE, L. F. D. Família, moralidade e religião: tensões contrastivas contemporâneas à busca de um modelo. In: VELHO, G.; DUARTE, L. F. D. (Org.). Gerações, família, sexualidade. Rio de Janeiro: Sete Letras, 2009. p. 17-45.

FOUCAULT, Michel. Le Triumphe social du plaisir sexuel: une conversation avec Michel Foucault. Dits et Écrits II - 1976-1988. Paris: Gallimard, 1994. p. 1127-1133.

GAMA, Guilherme Calmon Nogueira da. O companheirismo, uma espécie de família. 2. ed. São Paulo: Revista dos Tribunais, 2001.

GOODE, Erich; BEN-YEHUDA, Nachman. Moral panics: the social construction of deviance. Malden: Blackwell Publishing, 2003.

GUSTIN, Miracy Barbosa de Sousa. Das necessidades humanas aos direitos: ensaio de sociologia e filosofia do direito. Belo Horizonte: Del Rey, 1999. 
LACAN, Jacques. Os complexos familiares na formação do indivíduo. Tradução de Marco Antônio Coutinho Jorge e Potiguara Mendes da Silveira Júnior. Rio de Janeiro: Jorge Zahar Editor, 2002.

LANA, Fernanda Campos de Cerqueira; RODRIGUES JÚNIOR, Walsir Edson. O direito e a falta de afeto nas relações paterno filiais In: FIUZA, César; NAVES, Bruno Torquato de Oliveira; SÁ, Maria de Fátima Freire de. Direito civil: Atualidades IV - teoria e prática no direito privado. Belo Horizonte: Del Rey, 2010. p. 259-278.

LÉVI-STRAUSS, Claude. Raça e história. São Paulo: Abril Cultural, 1978. v. I. (Coleção Os Pensadores).

LOBO, Paulo Luiz Netto. Direito ao estado de filiação e direito à origem genética: uma distinção necessária. In: CONGRESSO BRASILEIRO DE DIREITO DE FAMÍLIA, IV: Anais ... Belo Horizonte: Del Rey, 2004. p. 323-346.

LORENZETTI, Ricardo Luis. Fundamentos do direito privado. Tradução de Vera Maria Jacob de Fradera. São Paulo: Revista dos Tribunais, 1998.

MACHADO, Diego Carvalho. Capacidade de agir e situações subjetivas existenciais: o exercício de situações existenciais pela pessoa adolescente a partir de um regime jurídico não codificado. Revista trimestral de direito civil, Rio de Janeiro, v.46, p. 3-51, abr./ jul. 2011.

MILTON, John. Paraíso perdido. Martin Claret: São Paulo, 2002.

MUNOZ-DARDÉ, Veronique. Doit-on alors abolir la famille? Revue de philosophie et sciences sociales, Paris, PUF, n. 2, 2001.

OLIVEIRA, Marcelo Andrade Cattoni de. Tutela jurisdicional e estado democrático de direito. Belo Horizonte: Del Rey, 1997.

PEREIRA, Rodrigo da Cunha. Uma principiologia para o direito de família. In: PEREIRA, Rodrigo da Cunha (Coord.). Família e dignidade humana: anais do $\mathrm{V}$ congresso brasileiro de direito de família. São Paulo: IOB Thomson, 2006. p. 843-851. 
PERLINGIERI, Pietro. Perfis do direito civil: introdução ao direito civil constitucional. Tradução de Maria Cristina de Cicco. 2. ed. Rio de Janeiro: Renovar, 2002.

PIANOVSKI, Carlos Eduardo. Famílias simultâneas e monogamia. In: PEREIRA, Rodrigo da Cunha (Coord.). Família e dignidade humana: anais do V congresso brasileiro de direito de família. São Paulo: IOB Thomson, 2006. p. 193-221.

PINTO, Paulo Mota. O direito ao livre desenvolvimento da personalidade. Boletim da Faculdade de Direito de Coimbra, Coimbra, v. 2, p. 155-190, jan. 1999.

QUINTANA, Mário. Caderno H. Porto Alegre: Globo, 1983.

REALE, Miguel. Lições preliminares de direito. 16. ed. São Paulo: Saraiva, 2000.

RODOTÀ, Stefano. Lo specchio di Stendhal: Riflessioni sulla riflessioni dei privatisti. Rivista Critica del Diritto Privato, Napoli, ano 15, 1997.

ROUDINESCO, Elizabeth. A família em desordem. Tradução de André Telles. Rio de Janeiro: Jorge Zahar, 2003.

SAMPAIO, Marília de Ávila e Silva. Aplicação dos direitos fundamentais nas relações entre particulares e a boa-fé objetiva. Rio de Janeiro: Lumen Juris, 2005.

SARMENTO, Daniel. A vinculação dos particulares aos direitos fundamentais no direito comparado e no Brasil. In: BARROSO, Luís Roberto (Org.). A nova interpretação constitucional: ponderação, direitos fundamentais e relações privadas. Rio de Janeiro: Renovar, 2006. p. 193-284.

SCOTT, Russel Parry. Relações conjugais em transformação. In: LIMA, Antônio Carlos de Souza (Org.). Antropologia \& Direito: temas antropológicos para estudos jurídicos. Brasília: LACED, Associação Brasileira de Antropologia, 2012. p. 495- 509. 
TEPEDINO, Gustavo. A disciplina civil-constitucional das relações familiares. In: TEPEDINO, Gustavo. Temas de direito civil. 2. ed. Rio de Janeiro: Renovar, 1999. p. 47-69.

THOMPSON, Kenneth. Moral panics. London: Routledge, 1998.

UZIEL, Ana Paula; MELLO, Luiz; GROSSI, Miriam Pillar.

Conjugalidades e parentalidades de gays, lésbicas e transgêneros no Brasil. Estudos Feministas, Florianópolis, v. 14, p. 481-487, 2006.

VELOSO, Zeno. Código civil comentado: direito de família. São Paulo: Atlas, 2003. v. XVII.

VILLELA, João Baptista. Liberdade e família. Belo Horizonte: Faculdade de Direito da UFMG, 1980.

WOLKMER, Antonio Carlos (Org.). Direitos humanos e filosofia jurídica na América Latina. Rio de Janeiro: Lumen Juris, 2004.

Recebido em: 27/04/2015

Aprovado em: 30/11/2015 